\title{
(2) OPEN ACCESS \\ Maternal caffeine consumption and pregnancy outcomes: a narrative review with implications for advice to mothers and mothers-to-be
}

\author{
Jack E. James
}

10.1136/bmjebm-2020-111432

- Additional material is published online only. To view please visit the journal online (http://dx.doi.org/ 10.1136/bmjebm-2020111432).

Correspondence to: Professor Jack E. James, Psychology, Reykjavik University, 101 Reykjavik, Iceland; jack@ru.is

\section{Check for updates}

๑ Author(s) (or their employer(s)) 2021. Re-use permitted under CC BY-NC. No commercial re-use. See rights and permissions. Published by BMJ.

To cite: James JE. BMJ Evidence-Based Medicine 2021;26:114-115.

\section{Abstract}

Objectives Caffeine is a habit-forming substance consumed daily by the majority of pregnant women. Accordingly, it is important that women receive sound evidence-based advice about potential caffeine-related harm. This narrative review examines evidence of association between maternal caffeine consumption and negative pregnancy outcomes, and assesses whether current health advice concerning maternal caffeine consumption is soundly based.

Methods Database searches using terms linking caffeine and caffeinated beverages to pregnancy outcomes identified 1261 English language peerreviewed articles. Screening yielded a total of 48 original observational studies and meta-analyses of maternal caffeine consumption published in the past two decades. The articles reported results for one or more of six major categories of negative pregnancy outcomes: miscarriage, stillbirth, low birth weight and/or small for gestational age, preterm birth, childhood acute leukaemia, and childhood overweight and obesity.

Results Of 42 separate sets of findings reported in 37 observational studies, 32 indicated significantly increased caffeine-related risk and 10 suggested no or inconclusive associations. Caffeine-related increased risk was reported with moderate to high levels of consistency for all pregnancy outcomes except preterm birth. Of 11 studies reporting 17 meta-analyses, there was unanimity among 14 analyses in finding maternal caffeine consumption to be associated with increased risk for the four outcome categories of miscarriage, stillbirth, low birth weight and/or small for gestational age, and childhood acute leukaemia. The three remaining meta-analyses were also unanimous in reporting absence of a reliable association between maternal caffeine consumption and preterm birth. No meta-analyses were identified for childhood overweight and obesity, although four of five original observational studies reported significant associations linking maternal caffeine consumption to that outcome category.

Conclusions The substantial majority finding from observational studies and meta-analyses is that maternal caffeine consumption is reliably associated with major negative pregnancy outcomes. Reported findings were robust to threats from potential confounding and misclassification. Among both observational studies and metaanalyses, there were frequent reports of significant dose-response associations suggestive of

\section{Summary box}

What is already known about this subject?

- Pharmacological actions of caffeine suggest potential threats to fetal development from maternal caffeine consumption.

- In recent decades, many observational studies of maternal caffeine consumption have reported potential increased risk for diverse negative pregnancy outcomes.

- However, current policy advice assumes that 'moderate' caffeine consumption during pregnancy is safe.

What are the new findings?

- Substantial majority findings from observational studies and metaanalyses indicate that maternal caffeine consumption is reliably associated with miscarriage, stillbirth, low birth weight and/or small for gestational age, childhood acute leukaemia and childhood overweight and obesity, but not preterm birth.

- Overall findings are robust to threats from potential confounding and misclassification.

- Findings frequently include significant dose-response associations suggestive of causation, and studies frequently report no threshold of consumption below which associations are absent.

How might it impact on clinical practice in the foreseeable future?

- Current evidence does not support assumptions about safe levels of maternal caffeine consumption.

- The cumulative scientific evidence supports advice to pregnant women and women contemplating pregnancy to avoid caffeine.

causation, and frequent reports of no threshold of consumption below which associations were absent. Consequently, current evidence does not support health advice that assumes 'moderate' 
caffeine consumption during pregnancy is safe. On the contrary, the cumulative scientific evidence supports pregnant women and women contemplating pregnancy being advised to avoid caffeine.

\section{Introduction}

There are almost no age, gender, geographical or cultural barriers to the consumption of caffeine, making it the most widely consumed psychoactive substance in history. ${ }^{1}$ Consumers include pregnant women, ${ }^{23} 82 \%$ of whom have been reported to consume caffeine daily in the USA ${ }^{4}$ and $91 \%$ in France. ${ }^{5}$ That caffeine is commonly consumed during pregnancy has been confirmed by reports of pharmacologically active concentrations of caffeine in the blood of a majority of newborn infants in France ${ }^{67}$ and the $\mathrm{UK}^{8}$

In 1980, the United States Food and Drug Administration (FDA) responded to findings of caffeine-induced teratogenic effects in rodents by issuing a warning advising pregnant women to restrict or abstain from the drug. ${ }^{9}$ However, current advice from relevant authorities, including the FDA, ${ }^{10}$ is generally more relaxed. For example, the American College of Obstetricians and Gynecologists (ACOG) ${ }^{11}$ advises that pregnant women may safely consume up to $200 \mathrm{mg}$ caffeine (the approximate equivalent of two cups of moderate-strength coffee) per day, and the same advice is contained in the (currently under review) Dietary Guidelines for Americans (DGAC). ${ }^{12}$

Similarly, the European Food Safety Authority (EFSA) states that maternal consumption of caffeine up to $200 \mathrm{mg}$ per day does "not give rise to safety concerns for the fetus" (p. 75), ${ }^{13}$ and the UK National Health Service (NHS) ${ }^{14}$ advises pregnant women to 'limit' daily intake to $200 \mathrm{mg}$. Notwithstanding the current broad consensus among health authorities, a recent study found that more than $40 \%$ of pregnant women in Finland reported consuming more than the widely promulgated recommended maximum of $200 \mathrm{mg}$ caffeine per day. ${ }^{15}$ This narrative review was undertaken for the dual purpose of (1) assessing current evidence concerning caffeine-related pregnancy outcomes, and (2) determining whether current health advice concerning maternal caffeine consumption is soundly based.

\section{Caffeine pharmacology: main mechanisms of action}

Knowledge of caffeine pharmacology suggests high biological plausibility for potential fetal harm from maternal consumption. ${ }^{16}{ }^{17}$ When consumed during pregnancy, caffeine readily crosses the placenta, exposing the fetus to concentrations of the drug similar to systemic levels in the mother. ${ }^{18}{ }^{19}$ The extent of diffusion of caffeine from maternal to fetal circulation is indicated by the presence of caffeine in fetal hair, with concentrations in the hair of newborns being found to correlate well with maternal caffeine consumption during the third trimester. ${ }^{15}$ In adults, caffeine is metabolised principally by cytochrome P450 enzymes (mono-oxygenase and xanthine oxidase enzymes) in the liver. However, because the P450 enzyme system remains undeveloped until infancy, ${ }^{20}{ }^{21}$ the kidneys are the main route of excretion in newborns with more than $80 \%$ of the drug passing unchanged in urine compared with only $2-4 \%$ of unchanged caffeine in adults. $^{22} 23$

As such, fetal caffeine clearance depends on maternal metabolism, the rate of which changes during pregnancy. Whereas clearance of caffeine in the first trimester is comparable to the non-pregnant state, the rate slows to one-half and then to about one-third during the second and third trimesters, respectively. ${ }^{24} 25$
Consequently, caffeine half-life increases from the usual adult rate of about 5 hours in the first trimester to about 18 hours by the 38th week of pregnancy. ${ }^{26}{ }^{27}$ The symptoms of nausea and vomiting that frequently accompany pregnancy-related changes in hormonal milieu and associated reduced rate of caffeine clearance help to explain the observation that women often spontaneously reduce their intake of caffeine when pregnant. ${ }^{24}$ Reduced intake means that plasma caffeine concentrations tend to be maintained at levels comparable to the pre-pregnant state instead of reaching the appreciably higher levels that would occur if intake remained unchanged.

Once ingested, caffeine is readily distributed throughout the body, with peak plasma concentrations occurring within about 40-60 min. ${ }^{28}$ Thereafter, caffeine exerts a variety of pharmacological actions at diverse sites, both centrally and peripherally. These actions are due mostly to competitive blockade of the neuromodulator adenosine, with $\mathrm{A}_{1}$ and $\mathrm{A}_{2 \mathrm{~A}}$ receptors appearing to be the primary targets. ${ }^{29}$ Effects include maintenance of transmitter release in the CNS (anti-somnolent effect), constriction of cerebral and coronary blood vessels, renal diuresis, respiratory bronchodilation and gastrointestinal acid secretion. ${ }^{30-32} \mathrm{~A}_{1}$ and $\mathrm{A}_{2 \mathrm{~A}}$ receptors also interact in functionally important ways with dopamine receptors, ${ }^{33} 34$ and caffeine stimulates secretion of the catecholamine stress hormones of epinephrine and norepinephrine. ${ }^{35}$ In turn, elevated catecholamine levels have the potential to increase placental vasoconstriction and increase fetal heart rate ${ }^{36}$ leading to impaired fetal oxygenation. ${ }^{37}$

Furthermore, habitual caffeine consumption leads to physical dependence, indicated by behavioural, physiological and subjective withdrawal effects (caffeine withdrawal syndrome) in response to even brief abstinence. ${ }^{38}$ Sleepiness, lethargy and headache are common symptoms, ${ }^{39}{ }^{40}$ which may occur following cessation of habitual intake of as little as $100 \mathrm{mg}$ (1 cup of coffee) per day and less. ${ }^{41}{ }^{42}$ With reference to standard criteria, principally those of the Diagnostic and Statistical Manual of Mental Disorders (DSM-V), ${ }^{43}$ caffeine has been labelled a 'drug of abuse'. ${ }^{44}$ Indeed, newborn infants of caffeineconsuming mothers have been reported to experience caffeine withdrawal symptoms including disturbed sleep, vomiting, increased frequency of irregular heartbeat and respiration, and increased fine tremors similar to neonatal narcotic abstinence syndrome. ${ }^{45} 46$

\section{Source literature for the review}

Articles about maternal caffeine consumption and pregnancy outcomes published in the past two decades comprised the source literature for this review. PubMed and Google Scholar databases were searched by the author using individual terms for diverse pregnancy outcomes combined with the term 'caffeine' and terms for the products that contain caffeine (eg, coffee, tea, cola and energy drinks). Articles were also hand-searched for additional records, and a total of 1261 English language articles published up to and including October 2019 were identified. Negative pregnancy outcomes were found to be comprehensively encompassed by six major categories: miscarriage, stillbirth, low birth weight and/or small for gestational age, preterm birth, childhood acute leukaemia, and childhood overweight and obesity. After screening for relevance and deletion of duplicates, the search yielded a total of 48 full-text articles comprising 37 original observational studies published since 2000 reporting 42 separate sets of outcomes (online supplementary table 1) and 11 articles published since 1998 reporting 17 meta-analyses (table 1). 
Table 1 Summary of caffeine-related odds ratios expressed as percentage increased risk of harm $(95 \% \mathrm{Cl})$ for diverse negative pregnancy outcomes reported in meta-analyses published since 1998

\begin{tabular}{|c|c|c|c|}
\hline Authors & Year & Risk, \% $(95 \% \mathrm{Cl})$ & Consumption, $\mathrm{mg} /$ day $^{\star}$ \\
\hline & & Miscarriage & \\
\hline Ferandes et $a l^{56}$ & 1998 & 36 (1.29 to 1.45$)$ & $\ll 150$ vs $\geq 150$ \\
\hline Greenwood et al $l^{57}$ & 2014 & 14 (1.10 to 1.19$)$ & Per 100 \\
\hline Li et $a l^{58}$ & 2015 & $32(1.24$ to 1.40$)$ & $\ll 150 v s \geq 150$ \\
\hline \multirow[t]{2}{*}{ Chen et $a l^{59}$} & 2016 & 7 (1.03 to 1.12$)$ & Per 100 \\
\hline & & Stillbirth & \\
\hline Greenwood et $a^{57}$ & 2014 & $19(1.05$ to 1.35$)$ & Per 100 \\
\hline \multirow[t]{2}{*}{ Chen et $a l^{59}$} & 2016 & $9(1.02$ to 1.16$)$ & Per 100 \\
\hline & & Low birth weight/Small for gestational age & \\
\hline Ferandes et $a l^{56}$ & 1998 & $51(1.39$ to 1.63$)$ & $\ll 150 v s \geq 150$ \\
\hline Santos et al ${ }^{80}$ & 1998 & $29(1.18$ to 1.41$) / 24$ (1.05 to 1.43$)$ & None/low vs high \\
\hline Chen et al ${ }^{81}$ & 2014 & 13 (1.06 to 1.21$)$ & Per 100 \\
\hline Greenwood et $a^{57}$ & 2014 & $7(1.01$ to 1.12$) / 10$ (1.06 to 1.14$)$ & Per 100 \\
\hline \multirow[t]{2}{*}{ Rhee et $\left.\right|^{82}$} & 2015 & $38(1.10$ to 1.73$)$ & Lowest vs highest \\
\hline & & Preterm birth & \\
\hline Santos et $a l^{80}$ & 1998 & Indeterminate & None/low vs high \\
\hline Maslova et al ${ }^{84}$ & 2010 & No 'important' association & Lowest vs highest \\
\hline \multirow[t]{2}{*}{ Greenwood et al $\left.\right|^{57}$} & 2014 & $2(-1.02$ to 1.06$)$ & Per 100 \\
\hline & & Childhood acute leukaemia & \\
\hline Milne et $a l^{89}$ & 2011 & 67 (1.20 to 2.32$)$ & None vs $3+$ cups coffee \\
\hline Cheng et $a l^{92}$ & 2014 & $72(1.32$ to 2.16$)$ & None/low vs highest \\
\hline Thomopoulos et al $l^{93}$ & 2015 & 57 (1.16 to 2.11$)$ & Lowest vs highest \\
\hline
\end{tabular}

*Level of maternal caffeine consumption ( $\mathrm{mg} /$ day when given) used as the basis for estimating risk of harm.

$\mathrm{Cl}$, confidence interval.

\section{Results}

\section{Miscarriage}

Online supplementary table 1 summarises nine observational studies of maternal caffeine consumption and miscarriage conducted since 2000. The findings were in substantial agreement, with eight studies reporting significant associations between caffeine and increased risk of miscarriage. ${ }^{47-54}$ The one inconsistent result was from the sole cross-sectional study ${ }^{55}$ in which a 'suggestive' association was reckoned to be due to recall bias. Notably, no such suspicion arises in relation to the cohort studies due to their prospective design, ${ }^{4850515354}$ and all of those reported significant caffeine-related negative outcomes.

There was a high level of consistency in the findings of the meta-analyses of caffeine and miscarriage, with all four listed in table 1 reporting significant caffeine-related increased risk. ${ }^{56-59}$ The odds ratio expressed as percentage increase in overall risk was $32 \%$ (95\% CI 1.24 to 1.40 ) in one stucy ${ }^{58}$ and 36\% (95\% CI 1.29 to 1.45 ) in another. ${ }^{56}$ Risk was also found to be dose-response related, with estimates of 7\% (95\% CI 1.03 to 1.12$)^{59}$ and $14 \%$ (95\% CI 1.10 to 1.19$)^{57}$ increased risk for each increment of $100 \mathrm{mg}$ caffeine consumed per day during pregnancy, and 19\% (95\% CI 1.16 to 1.23$)^{58}$ for each $150 \mathrm{mg}$ increment.

\section{Stillbirth}

Findings for stillbirth were largely consistent, with four of five observational studies reporting caffeine-related increased risk (online supplementary table 1) ${ }^{60-66}$ Notably, the sole inconsistent study reporting a non-significant result for stillbirth (loss after 20 weeks of pregnancy) reported a significantly increased risk for miscarriage (loss before 20 weeks). ${ }^{53}$ In the other studies, the increased risk for high caffeine-consuming women was variously reported to be approximately twofold (95\% CI 1.23 to 4.41), ${ }^{62}$ threefold (95\% CI 1.5 to 5.9$)^{60}$ and fivefold (95\% CI 1.6 to 16.4$)^{63}$ after adjustment for potential confounders.

One study examined polymorphisms of the genes that encode enzymes responsible for caffeine metabolism in order to test the hypothesis that 'slow metabolisers' may be at increased risk. ${ }^{61}$ While no single genotype was associated with risk, a combination of three separate genes that contribute to a slower rate of caffeine metabolism was found to be associated with an almost twofold increased risk compared with other genotype combinations. Regarding relevant meta-analyses, table 1 shows that both of two studies reported significant associations, with increased risk of stillbirth per $100 \mathrm{mg}$ caffeine per day estimated in one study to be $9 \%(95 \% \text { CI } 1.02 \text { to } 1.12)^{59}$ and in the other to be $19 \%$ (95\% CI 1.05 to 1.35$).^{57}$

\section{Low birth weight (LBW) and/or small for gestational age (SGA)}

It has long been known that caffeine in the diet of pregnant rodents contributes to lower fetal weight. ${ }^{64-66}$ Although consumption in the order of $70 \mathrm{mg} / \mathrm{kg}$ or more per day has been typical for animal experiments, significant growth reduction in rat offspring has also been reported for as little as $10 \mathrm{mg} / \mathrm{kg}$ of daily caffeine (the approximate equivalent in humans of 7 cups of coffee) ${ }^{67}$ Online supplementary table 1 shows that, of 13 observational studies comprising 12 cohort studies and one case-control study, four reported results for LBW alone, ${ }^{68-71}$ three for SGA alone, ${ }^{72-74}$ and six for both outcomes. ${ }^{45-79}$

Of the 10 studies reporting results for LBW, seven reported caffeine-related increased risk ${ }^{4} 68-717778$ and three reported no association. $^{75} 7679$ Of nine studies reporting results for SGA, seven reported caffeine-related increased risk ${ }^{411} 737476-78$ and two reported no association. ${ }^{75} 79$ Thus, of the 13 studies of LBW and/ or SGA, all but two ${ }^{75} 79$ reported caffeine-related increased risk for 
one or both LBW and SGA. Addressing the question of comparative risk, the CARE Study Group ${ }^{69}$ reported that the caffeinerelated risk for LBW in that study was similar to the risk associated with maternal alcohol intake.

Notwithstanding occasional null results, the substantial consistency in findings from original observational studies of caffeine and LBW/SGA is reflected in meta-analyses. Of the five relevant meta-analyses listed in table 1 , all reported results for LBW $^{56} 57$ 80-8280-82 and two reported results for SGA. ${ }^{57}{ }^{80}$ All five meta-analyses for LBW reported a caffeine-related increased risk. ${ }^{56} 57718082$ Dose-response analyses found that every additional $100 \mathrm{mg}$ per day of maternal caffeine was associated with an increased risk for LBW of 7\% (95\% CI 1.01 to 1.12) in one of two meta-analyses $^{57}$ and 13\% (95\% CI 1.06 to 1.21 ) in the second. ${ }^{81}$

One of the two meta-analyses for SGA reported an aggregated increased risk of $24 \%$ (95\% CI 1.05 to 1.43 ) for high caffeineconsuming mothers, ${ }^{80}$ and the second reported an increased risk of $10 \%$ (95\% CI 1.06 to 1.14) for each additional intake of $100 \mathrm{mg}$ caffeine. ${ }^{57}$ Notably, similar and higher estimates of risk for SGA were reported in recent observational studies not included in the meta-analyses. Of three such studies, two reported good agreement for increased risk associated with moderate caffeine intake of $16 \%$ (95\% CI 1.10 to 1.23$)^{74}$ and $18 \%$ (95\% CI 1.10 to 1.27$){ }^{73}$ and the third reported an increased risk of 57\% (95\% CI 1.16 to 2.13) associated with higher intake. ${ }^{4}$

\section{Preterm birth}

Online supplementary table 1 shows that, of four observational studies published since 2000, two reported maternal caffeine consumption to be associated with increased risk of preterm birth $^{73}{ }^{79}$ and two reported no association. ${ }^{68} 83$ Of three metaanalyses listed in table 1, one reported that high heterogeneity within the published data prevented computation of reliable pooled estimates ${ }^{80}$ and two concluded that maternal caffeine consumption is unrelated to risk of preterm birth, ${ }^{57} 84$ Thus, available meta-analyses suggest that maternal caffeine consumption is not associated with increased risk of preterm birth. On the other hand, it might be noted that publication of all three meta-analyses preceded the two observational studies that reported significant associations. $^{73} 79$ One of those two studies reported an increased risk of preterm birth of $28 \%$ (95\% CI 1.03 to 1.58) for each increment of $100 \mathrm{mg}$ caffeine consumed per day during pregnancy, ${ }^{79}$ and the second reported a $94 \%$ (95\% CI 1.12 to 3.37) increased risk for the highest quartile of maternal caffeine consumption compared with the lowest quartile. ${ }^{73}$

\section{Childhood acute leukaemia}

Online supplementary table 1 summarises findings from six casecontrol studies of caffeine-related risk of childhood leukaemia, including acute lymphocytic (lymphoblastic) leukaemia (ALL) which accounts for about 75\% of childhood leukaemias and is the most common cause of death from cancer in children, and acute myeloid leukaemia (AML) which accounts for most of the remaining cases of childhood leukaemia. ${ }^{85}$ Three of the six studies reported significant associations. ${ }^{86-88}$ Among the remaining three studies, two that found no overall association reported significant associations for mothers who were non-smokers and had a comparatively high caffeine intake. ${ }^{89} 90$ An interaction with smoking is plausible in that smoking is known to accelerate caffeine metabolism, thereby offering smokers potential limited protection against the harmful effects of caffeine. ${ }^{89}$ The remaining study reported that the association between maternal caffeine consumption and risk of childhood acute leukaemia was unclear. ${ }^{91}$
Notwithstanding mixed results from observational studies, all three relevant meta-analyses listed in table 1 concluded that maternal caffeine consumption is associated with an increased risk of childhood acute leukaemia. This includes a meta-analysis conducted by the authors of one of the observational studies that reported equivocal findings. ${ }^{89}$ The other two meta-analyses are more recent, one of which reported that high maternal caffeine consumption was associated with a 65\% (95\% CI 1.28 to 2.12) increased risk for ALL and 58\% (95\% CI 1.20 to 2.08) increased risk for AML. ${ }^{92}$ The same study reported a linear dose-response relationship for both outcomes. A broadly similar increased risk of 43\% (95\% CI 1.22 to 1.68) was reported for ALL in the most recent meta-analysis, and a substantially larger increased risk of 2.5-fold (95\% CI 1.59 to 3.57) was reported for AML. ${ }^{93}$

\section{Childhood overweight and obesity}

Animal studies have shown that maternal caffeine exposure is associated with long-term changes in metabolic functions under the control of the hypothalamic-pituitary-adrenal axis. ${ }^{9495}$ Such changes affect regulation by adenosine and/or its receptors involved in development, ${ }^{96} 97$ while also influencing placental expression and transport of leptins essential for regulating appetite. ${ }^{98}$ Consequently, the role of maternal caffeine in childhood obesity has emerged as an area of focus in recent human research.

Online supplementary table 1 summarises the findings of four cohort studies $^{7099-101}$ and one case-control study, ${ }^{102}$ all published since 2015. With one exception, the studies reported significant associations between maternal caffeine consumption and increased risk of childhood overweight, adiposity and/or obesity. The inconsistent finding was reported in the case-control study, which used data collected more than 50 years ago. ${ }^{102}$ A doseresponse association was reported in one study, with children of mothers whose caffeine consumption was highest $(\geq 150 \mathrm{mg}$ of caffeine per day) experiencing a greater than twofold overall increased risk of obesity (OR 2.37; 95\% CI 1.24 to 4.52) at age 5 years compared with children of mothers who consumed no caffeine during pregnancy. ${ }^{99}$

There appear to be no published meta-analyses of maternal caffeine consumption and childhood overweight and obesity, although a recent systematic review concluded that there may be a significant association. ${ }^{103}$ Indeed, the authors suggested that maternal caffeine consumption could be a contributing factor in the recent rise in population prevalence of childhood overweight and obesity, and advised that consideration be given to revising current consumption guidelines.

\section{Discussion}

Bearing in mind occasional discrepant findings, a substantial level of consistency was found among the 42 sets of observational findings summarised in online supplementary table 1 . Overall, 32 studies reported a significantly increased risk of negative pregnancy outcomes associated with maternal caffeine consumption and 10 reported no or equivocal association. On the other hand, relevant meta-analyses were unanimous in their main findings. Excluding the outcome of childhood overweight and obesity (for which no meta-analysis was identified), table 1 shows 14 metaanalyses were unanimous in reporting a significant caffeinerelated increased risk of harm. Specifically, maternal caffeine consumption was reported to be associated with increased risk by all four meta-analyses of miscarriage, both of two meta-analyses of stillbirth, all five meta-analyses of LBW and/or SGA and all three meta-analyses of childhood acute leukaemia. Only preterm birth differed in pattern, where all three relevant meta-analyses 
found maternal caffeine consumption not to be reliably associated with increased risk.

\section{Are caffeine-related negative pregnancy outcomes merely unexplained associations?}

Rational health advice about caffeine exposure during pregnancy depends crucially on the extent to which the evidence of association is thought to be indicative of causation. Therefore, despite extensive consistency in the reporting of increased risk of harm associated with maternal caffeine consumption, it is reasonable to ask: Do methodological shortcomings limit inferences of causation within the large body of evidence of association? In reply, apart from specific potential limitations examined below, it may be said that the likelihood of causation (rather than mere association) is supported by the many reports of observed dose-response relationships between the amount of caffeine consumed during pregnancy and the risk of negative pregnancy outcomes. Implication of causation is also rendered more salient by reports of no threshold of consumption below which associations are absent. Overall, then, likely causation is supported by a compelling body of evidence, both theoretical (ie, biological plausibility) and empirical, including a strong consensus among observational studies and particularly meta-analyses, dose-response relationships and reported absence of threshold effects.

In light of relevant theoretical considerations and abundant empirical evidence, it is pertinent to consider the role of industry in the caffeine and pregnancy narrative, especially with regard to questions of causation. In the late 1970s the FDA announced possible removal of caffeine from its list of food additives 'generally recognised as safe'. That threat prompted soft drink manufacturers to fund the establishment of the International Life Sciences Institute (ILSI). ${ }^{104-106}$ Headquartered in Washington, DC, ILSI expanded rapidly to include a broad global alliance of corporate members whose worldwide influence on public health policy, including food and food additives, cigarette smoking and the use of agrochemicals, has been for many years the subject of analysis and criticism from authoritative international sources. ${ }^{107-113}$

Mobilised to counter public concern about the general safety of caffeine, ILSI was well positioned to respond to more specific concerns highlighted in the 1980 FDA warning about caffeine and pregnancy. ${ }^{9}$ Through its Caffeine Working Group and affiliated industry organisations, including the American Beverage Association and the National Coffee Association, ILSI has supported the production of a body of published articles depicting caffeine as a benign substance posing little or no threat to fetal health and development. ${ }^{114-121}$ Scientific evidence to the contrary has been portrayed in that literature as methodologically flawed due to confounding from uncontrolled variables.

Spurious conclusions have been a recurring feature of industry-affiliated commentary. ${ }^{114-121}$ For example, one review concluded that the "evidence does not support a positive relationship between caffeine consumption and adverse reproductive or perinatal outcomes" (p. 2573, emphasis added), ${ }^{117}$ while another concluded that daily consumption of caffeine is "not associated with adverse reproductive and developmental effects" (p. 637, emphasis added). ${ }^{119}$ Yet, in reality, even industry-affiliated commentaries agree with independent opinion that maternal caffeine consumption is associated with (ie, has a 'positive relationship' with) negative pregnancy outcomes. Notwithstanding universal agreement that relevant associations have been established as undeniable fact, ILSI-affiliated literature ${ }^{114-121}$ has promulgated an opportunistic deception by conflating association and causation, wherein legitimate questions about causation have been used to make false claims ${ }^{117} 119$ about absence of evidence of association.

The main threats to causal inference of harm from maternal caffeine consumption are generally recognised to be potential confounding from extraneous variables and possible misclassification of exposure and outcome variables. However, contrary to ILSI-affiliated representations of the research literature, ${ }^{114-121}$ caffeine and pregnancy as a field of research is noteworthy for the effort that has been invested in the search for and control of potential confounders, and the frequent use of objective measurement to minimise risk of misclassification. With regard to potential confounding, diverse demographic variables, behaviour patterns and living environment have been repeatedly examined, including age at conception, health status, pregnancy history, use of oral contraceptives, alcohol and other substance use, exposure to pollutants, maternal body mass, physical activity, religion, education and occupation. In addition to these and other variables that have been examined, the accepted main potential confounders, and the ones highlighted in ILSI-affiliated publications, are pregnancy symptoms (also referred to as pregnancy signal symptoms), potential recall bias and maternal cigarette smoking.

Pregnancy symptoms such as nausea and vomiting in early pregnancy are predictive of a healthy pregnancy and, as alluded to above, are often accompanied by a spontaneous reduction in caffeine intake. ${ }^{122}{ }^{123}$ Accordingly, it was long ago hypothesised that the association between negative pregnancy outcomes and maternal caffeine consumption could be due to a tendency among women who experience few symptoms of pregnancy and are at higher risk of experiencing negative pregnancy outcomes to also consume more caffeine. ${ }^{124}$ However, that hypothesis has been extensively examined and has been repeatedly disconfirmed in diverse studies spanning nearly three decades. ${ }^{48} 49$ 51-54 62124125 Notably, disconfirmation has been decisive in the many studies in which potential confounding was controlled by measuring pregnancy symptoms and caffeine consumption prospectively prior to any knowledge of subsequent pregnancy outcomes.

Recall bias has also been shown not to be a sustainable challenge for the straightforward reason that a large proportion of the extant research consists of prospective cohort studies in which caffeine exposure was measured, often confirmed by objective biomarkers, before conception or during early pregnancy, prior to knowledge of pregnancy outcomes. Similarly, prospective measurement, including use of biomarkers, has shown that cigarette smoking is an unlikely source of serious confounding. Indeed, concerns about smoking as a source of confounding have been conclusively disconfirmed by frequent reports of significant caffeine-related negative pregnancy outcomes in nonsmokers and never smokers. ${ }^{47} 49-5360626369788689$

\section{Are randomised controlled trials the solution?}

Concern about potential confounding in observational studies raises the question as to whether research into caffeine and pregnancy outcomes would yield clearer answers if randomised controlled trials were employed. That question was the subject of a meta-analysis, ${ }^{126}$ which identified only one relevant study ${ }^{127}$ in which coffee-consuming women at about the twentieth week of pregnancy were randomly assigned to two groups. The women were supplied with coffee (either regular or decaffeinated) and asked to consume the supplied coffee in place of their usual product. From the results, the authors concluded that a "moderate reduction in caffeine intake in the second half of pregnancy has no effect on birth weight or length of gestation" (p. 5). ${ }^{127}$ 
However, as the authors of the meta-analysis observed, ${ }^{126}$ the trial results are of doubtful value due to several limitations. Notably, the trial is relevant only to questions about potential outcomes attributable to caffeine consumption during the latter stages of pregnancy. In contrast, virtually all of the relevant science agrees that threats to the developing fetus from caffeine exposure occur primarily in the first trimester of pregnancy. In addition, there was evidently a substantial level of participant non-compliance with the requirements of the study. This included participants drinking coffee other than that which had been supplied, and only about half in both groups returning diaries in which they had been requested to record their caffeine intake. ${ }^{127}$

Apart from practical challenges, Jahanfar and Jaafar ${ }^{126}$ questioned the ethicality of conducting randomised controlled trials of caffeine in pregnant women. Ironically, the raising of potential ethical issues in this instance is clear acknowledgement of concerns about possible harm from maternal caffeine consumption. In turn, that ethical paradox highlights a troubling feature of current health advice. Predicated on the fragile assumption that 'moderate' caffeine consumption during pregnancy is safe, current advice could be said to involve experimentation, the potential negative consequences of which are exacerbated due to the 'experiment' being uncontrolled and unmonitored.

\section{Implications for advice guidelines}

Much current advice about maternal caffeine consumption is guided by belief that 'moderate' caffeine consumption during pregnancy is safe. Yet, in some instances at least, that belief is based on incomplete analysis. For example, the $\mathrm{DGAC}^{12}$ used a metaanalysis by Greenwood et $a l^{57}$ as its main source for concluding that the "risk of miscarriage, stillbirth, low birth weight, and SGA births is minimal" (p. 303). However, that claim is essentially untenable even in the context of the evidence reviewed by both groups. Notably, neither Greenwood et $a l^{57}$ nor the DGAC ${ }^{12}$ attempted to estimate the potential burden of disease implied by the risk estimates they themselves reported. In reality, aside from the suffering of individuals, the cumulative population impact of the outcomes reported by Greenwood et $a l^{57}$ and accepted by the DGAC $^{12}$ are demonstrably neither 'modest' nor 'minimal'.

Obviously, not all pregnant women consume the reputedly safe level of $200 \mathrm{mg}$ caffeine per day. Whereas many consume less or none, a sizeable proportion regularly consumes more. ${ }^{15}$ In that regard, the dose-response estimates of caffeine-related harm reported by Greenwood et $\mathrm{al}^{57}$ may be used to gauge the potential population impact assuming a uniform maximum 'safe' level of consumption by all pregnant women. Under those circumstances, the minimum impact, by any reckoning, would be of the order of tens of thousands of avoidable negative pregnancy outcomes per year in the USA alone. Moreover, that number may be assumed to be less than a larger total of potential harm, because it relates only to miscarriage, stillbirth, LBW and SGA while ignoring the negative outcomes of childhood leukaemia and childhood overweight/obesity for which there is good evidence of caffeine-related harm.

\section{Conclusions}

It is generally accepted that chronic exposure to chemicals during pregnancy is cause for concern. When the chemical of interest is caffeine, a near universally consumed habitforming substance of no nutritional value, the need for caution is compelling. There is substantial cumulative evidence of an association between maternal caffeine consumption and diverse negative pregnancy outcomes. Indicative of causation, observational studies and meta-analyses alike have reported dose-response associations with some studies also finding no threshold of consumption below which associations with negative outcomes are absent. Crucially, the evidence has proved to be decidedly robust to threats from potential confounding and misclassification.

An extensive body of scientific evidence from original observational studies and meta-analyses provides persuasive confirmation of increased risk from maternal caffeine consumption for at least five major negative pregnancy outcomes: miscarriage, stillbirth, lower birth weight and/or small for gestational age, childhood acute leukaemia and childhood overweight and obesity. Of the outcomes reviewed, the risk of preterm birth is the only one not found to be reliably associated with maternal caffeine consumption. Hence, current advice such as that issued by ACOG,${ }^{11}$ the DGAC, ${ }^{12}$ EFSA $^{13}$ and the NHS ${ }^{14}$ is not consistent with the level of threat indicated by biological plausibility of harm and extensive empirical evidence of actual harm. Accordingly, current health recommendations concerning caffeine consumption during pregnancy are in need of radical revision. Specifically, the cumulative scientific evidence supports pregnant women and women contemplating pregnancy being advised to avoid caffeine.

Correction notice This article has been corrected since it appeared Online First. Table 2 has been removed, and minor changes have been made to the paragraph preceding the Conclusions section.

Acknowledgements Information Specialist, Unnur Valgeirsdóttir, Reykjavík University Library, contributed bibliographic support.

Contributors JEJ is the sole author of the submitted article.

Funding This manuscript was prepared in the course of the author's employment as a Professor at Reykjavík University.

Disclaimer No additional or dedicated funding was received. Competing interests None declared.

Patient consent for publication Not required.

Provenance and peer review Not commissioned; externally peer reviewed.

Data availability statement Data sharing not applicable as no datasets generated and/or analysed for this study. All source materials for this review are available through publiclyaccessible sites.

Open access This is an open access article distributed in accordance with the Creative Commons Attribution Non Commercial (CC BY-NC 4.0) license, which permits others to distribute, remix, adapt, build upon this work non-commercially, and license their derivative works on different terms, provided the original work is properly cited, appropriate credit is given, any changes made indicated, and the use is non-commercial. See: http://creativecommons.org/licenses/by-nc/4.0/.

ORCID iD

Jack E. James http://orcid.org/0000-0003-3918-062X

\section{References}

1 James JE. Caffeine and health. London: Academic Press, 1991.

2 Frary CD, Johnson RK, Wang MQ. Food sources and intakes of caffeine in the diets of persons in the United States. J Am Diet Assoc 2005;105:110-3. 
3 Fulgoni VL, Keast DR, Lieberman HR. Trends in intake and sources of caffeine in the diets of US adults: 2001-2010. Am J Clin Nutr 2015;101:1081-7.

4 Hoyt AT, Browne M, Richardson S, et al. Maternal caffeine consumption and small for gestational age births: results from a population-based casecontrol study. Matern Child Health J 2014;18:1540-51.

5 Galéra C, Bernard JY, van der Waerden J, et al. Prenatal caffeine exposure and child IQ at age 5.5 years: the EDEN mother-child cohort. Biol Psychiatry 2016;80:720-6.

6 Brazier JL, Salle B. Conversion of theophylline to caffeine by the human fetus. Semin Perinatol 1981;5:315-20.

7 Dumas M, Gouyon JB, Tenenbaum D, et al. Systematic determination of caffeine plasma concentrations at birth in preterm and full-term infants. Dev Pharmacol Ther 1982;4(Suppl):182-6.

8 van't Hoff W. Caffeine in pregnancy. Lancet 1982;1:1020.

9 Goyan J. Food and drug administration news release, no. P80-36. Washington DC: FDA, 1980.

10 Food and Drug Administration. Spilling the beans: how much caffeine is too much? 2018. Available: https://www.fda.gov/consumers/consumerupdates/spilling-beans-how-much-caffeine-too-much

11 American College of Obstetricians and Gynecologists. Committee opinion: moderate caffeine consumption during pregnancy, no. 462. 2010, 2016. Available: https://www.acog.org/-/media/Committee Opinions/ Committee on Obstetric Practice/co462.pdf8

12 Dietary Guidelines Advisory Committee. Scientific report of the 2015 Dietary Guidelines Advisory Committee: Advisory report to the Secretary of Health and Human Services and the Secretary of Agriculture. Washington DC: U.S. Department of Agriculture, Agricultural Research Service, 2015. https://health.gov/sites/default/files/2019-09/ScientificReport-of-the-2015-Dietary-Guidelines-Advisory-Committee.pdf

13 European Food Safety Authority. Panel on dietetic products, nutrition and allergies. Scientific opinion on the safety of caffeine. EFSA $J$ 2015;13:4102.

14 National Health Service. Should I limit caffeine during pregnancy? 2018. Available: https://www.nhs.uk/common-health-questions/pregnancy/ should-i-limit-caffeine-during-pregnancy/

15 Lehtonen A, Uusitalo L, Auriola S, et al. Caffeine content in newborn hair correlates with maternal dietary intake. Eur J Nutr 2020;158.

16 James JE. Understanding caffeine: a biobehavioral analysis. Thousand Oaks, CA: Sage Publications, 1997.

17 James JE, Paull I. Caffeine and human reproduction. Rev Environ Health 1985;5:151-67.

18 Horning MG, Butler CM, Howlin J, et al. Drug metabolism in the human neonate. Life Sci 1975;16:651-71.

19 Darakjian LI, Kaddoumi A. Physiologically based pharmacokinetic/ pharmacodynamic model for caffeine disposition in pregnancy. Mol Pharm 2019;16:1340-9.

20 Parsons WD, Neims AH. Prolonged half-life of caffeine in healthy TEM newborn infants. J Pediatr 1981;98:640-1.

21 Pearlman SA, Duran C, Wood MA, et al. Caffeine pharmacokinetics in preterm infants older than 2 weeks. Dev Pharmacol Ther 1989;12:65-9.

22 Shrestha B, Jawa G. Caffeine citrate - is it a silver bullet in neonatology? Pediatr Neonatol 2017;58:391-7.

23 Somani SM, Gupta P. Caffeine: a new look at an age-old drug. Int J Clin Pharmacol Res 1988;26:521-33.

24 Aldridge A, Bailey J, Neims AH. The disposition of caffeine during and after pregnancy. Semin Perinatol 1981;5:310-4.

$25 \mathrm{Yu}$ T, Campbell SC, Stockmann C, et al. Pregnancy-induced changes in the pharmacokinetics of caffeine and its metabolites. J Clin Pharmacol 2016;56:590-6

26 Knutti R, Rothweiler H, Schlatter C. Effect of pregnancy on the pharmacokinetics of caffeine. Eur J Clin Pharmacol 1981;21:121-6.

27 Sasaki S, Limpar M, Sata F, et al. Interaction between maternal caffeine intake during pregnancy and CYP1A2 C164A polymorphism affects infant birth size in the Hokkaido study. Pediatr Res 2017;82:19-28.

28 Rall TW. Drugs used in the treatment of asthma. The methylxanthines, cromolyn sodium, and other agents. In: Gilman AG, Rall TW, Nies AS, et al, eds. Goodman and Gilman's the pharmacological basis of therapeutics. New York: Pergamon, 1990: 618-37.
29 Dunwiddie TV, Masino SA. The role and regulation of adenosine in the central nervous system. Annu Rev Neurosci 2001;24:31-55.

30 Franchetti P, Messini L, Cappellacci L, et al. 8-Azaxanthine derivatives as antagonists of adenosine receptors. $J$ Med Chem 1994;37:2970-5.

31 LeBlanc J, Soucy J. Hormonal dose-response to an adenosine receptor agonist. Can J Physiol Pharmacol 1994;72:113-6.

32 Carter AJ, O'Connor WT, Carter MJ, et al. Caffeine enhances acetylcholine release in the hippocampus in vivo by a selective interaction with adenosine A1 receptors. J Pharmacol Exp Ther 1995;273:637-42.

33 Garrett BE, Holtzman SG. D1 and D2 dopamine receptor antagonists block caffeine-induced stimulation of locomotor activity in rats. Pharmacol Biochem Behav 1994;47:89-94.

34 Ferré S. Mechanisms of the psychostimulant effects of caffeine: implications for substance use disorders. Psychopharmacology 2016;233:1963-79.

35 Lane JD, Pieper CF, Phillips-Bute BG, et al. Caffeine affects cardiovascular and neuroendocrine activation at work and home. Psychosom Med 2002;64:595-603.

36 Kirkinen P, Jouppila P, Koivula A, et al. The effect of caffeine on placental and fetal blood flow in human pregnancy. Am J Obstet Gynecol 1983;147:939-42.

37 Resch BA, Papp JG. Effects of caffeine on the fetal heart. Am J Obstet Gynecol 1983;146:231-2.

38 Juliano LM, Griffiths RR. A critical review of caffeine withdrawal: empirical validation of symptoms and signs, incidence, severity, and associated features. Psychopharmacology 2004;176:1-29.

39 James JE. Acute and chronic effects of caffeine on performance, mood, headache, and sleep. Neuropsychobiology 1998;38:32-41.

40 Phillips-Bute BG, Lane JD. Caffeine withdrawal symptoms following brief caffeine deprivation. Physiol Behav 1997;63:35-9.

41 Lieberman HR, Wurtman RJ, Emde GG, et al. The effects of low doses of caffeine on human performance and mood. Psychopharmacology 1987;92:308-12.

42 Smit HJ, Rogers PJ. Effects of low doses of caffeine on cognitive performance, mood and thirst in low and higher caffeine consumers. Psychopharmacology 2000;152:167-73.

43 American Psychiatric Association. Diagnostic and statistical manual of mental disorders. 5th edn. Washington, DC: American Psychiatric Association, 2013.

44 Dos Santos MKF, Gavioli EC, Rosa LS, et al. Craving espresso: the dialetics in classifying caffeine as an abuse drug. Naunyn Schmiedebergs Arch Pharmacol 2018;391:1301-18.

45 Hadeed A, Siegel S. Newborn cardiac arrhythmias associated with maternal caffeine use during pregnancy. Clin Pediatr 1993;32:45-7.

46 McGowan JD, Altman RE, Kanto WP. Neonatal withdrawal symptoms after chronic maternal ingestion of caffeine. South Med J 1988;81:1092-4.

47 Cnattingius S, Signorello LB, Annerén G, et al. Caffeine intake and the risk of first-trimester spontaneous abortion. $N$ Engl J Med 2000;343:1839-45.

48 Wen W, Shu X0, Jacobs DR, et al. The associations of maternal caffeine consumption and nausea with spontaneous abortion. Epidemiology 2001;12:38-42.

49 Giannelli M, Doyle P, Roman E, et al. The effect of caffeine consumption and nausea on the risk of miscarriage. Paediatr Perinat Epidemiol 2003;17:316-23.

50 Khoury JC, Miodovnik M, Buncher CR, et al. Consequences of smoking and caffeine consumption during pregnancy in women with type 1 diabetes. J Matern Fetal Neonatal Med 2004;15:44-50.

51 Weng X, Odouli R, Li D-K. Maternal caffeine consumption during pregnancy and the risk of miscarriage: a prospective cohort study. Am J Obstet Gynecol 2008;198:279.e1-8.

52 Stefanidou EM, Caramellino L, Patriarca A, et al. Maternal caffeine consumption and sine causa recurrent miscarriage. Eur J Obstet Gynecol Reprod Biol 2011;158:220-4.

53 Gaskins AJ, Rich-Edwards JW, Williams PL, et al. Pre-pregnancy caffeine and caffeinated beverage intake and risk of spontaneous abortion. Eur J Nutr 2018;57:107-17. 
54 Purdue-Smithe AC, Kim K, Schisterman EF, et al. Caffeinated beverage intake and serum caffeine metabolites and risk of pregnancy loss. Fertil Steril 2019;112:e27.

55 Savitz DA, Chan RL, Herring AH, et al. Caffeine and miscarriage risk. Epidemiology 2008;19:55-62.

56 Fernandes 0, Sabharwal M, Smiley T, et al. Moderate to heavy caffeine consumption during pregnancy and relationship to spontaneous abortion and abnormal fetal growth: a meta-analysis. Reprod Toxicol 1998;12:435-44.

57 Greenwood DC, Thatcher NJ, Ye J, et al. Caffeine intake during pregnancy and adverse birth outcomes: a systematic review and dose-response metaanalysis. Eur J Epidemiol 2014;29:725-34.

58 Li J, Zhao H, Song J-M, et al. A meta-analysis of risk of pregnancy loss and caffeine and coffee consumption during pregnancy. Int J Gynaecol Obstet 2015;130:116-22.

59 Chen L-W, Wu Y, Neelakantan N, et al. Maternal caffeine intake during pregnancy and risk of pregnancy loss: a categorical and doseresponse meta-analysis of prospective studies. Public Health Nutr 2016;19:1233-44.

60 Wisborg K, Kesmodel U, Bech BH, et al. Maternal consumption of coffee during pregnancy and stillbirth and infant death in first year of life: prospective study. BMJ 2003;326:420.

61 Bech BH, Autrup H, Nohr EA, et al. Stillbirth and slow metabolizers of caffeine: comparison by genotypes. Int J Epidemiol 2006;35:948-53.

62 Matijasevich A, Barros FC, Santos IS, et al. Maternal caffeine consumption and fetal death: a case-control study in Uruguay. Paediatr Perinat Epidemiol 2006;20:100-9.

63 Greenwood DC, Alwan N, Boylan S, et al. Caffeine intake during pregnancy, late miscarriage and stillbirth. Eur J Epidemiol 2010;25:275-80.

64 Fujii T, Nishimura H. Adverse effects of prolonged administration of caffeine on rat fetus. Toxicol Appl Pharmacol 1972;22:449-57.

65 Gilbert EF, Pistey WR. Effect on the offspring of repeated caffeine administration to pregnant rats. J Reprod Fertil 1973;34:495-9.

66 Thayer PS, Kensler CJ. Exposure of four generations of mice to caffeine in drinking water. Toxicol Appl Pharmacol 1973;25:169-79.

67 Dunlop M, Court JM. Effects of maternal caffeine ingestion on neonatal growth in rats. Biol Neonate 1981;39:178-84.

68 Bracken MB, Triche EW, Belanger K, et al. Association of materna caffeine consumption with decrements in fetal growth. Am J Epidemiol 2003;157:456-66.

69 CARE Study Group. Maternal caffeine intake during pregnancy and risk of fetal growth restriction: a large prospective observational study. $B M J$ 2008;337:a233.

70 Voerman E, Jaddoe VWV, Gishti 0, et al. Maternal caffeine intake during pregnancy, early growth, and body fat distribution at school age. Obesity 2016;24:1170-7.

71 Chen L-W, Fitzgerald R, Murrin CM, et al. Associations of maternal caffeine intake with birth outcomes: results from the Lifeways cross generation cohort study. Am J Clin Nutr 2018;108:1301-8.

72 Klebanoff MA, Levine RJ, Clemens JD, et al. Maternal serum caffeine metabolites and small-for-gestational age birth. Am J Epidemiol 2002;155:32-7.

73 Kobayashi S, Sata F, Murata K, et al. Dose-dependent associations between prenatal caffeine consumption and small for gestational age, preterm birth, and reduced birthweight in the Japan Environment and Children's Study. Paediatr Perinat Epidemiol 2019;33:185-94.

74 Modzelewska D, Bellocco R, Elfvin A, et al. Caffeine exposure during pregnancy, small for gestational age birth and neonatal outcome - results from the Norwegian Mother and Child Cohort Study. BMC Pregnancy Childbirth 2019;19:80.

75 Clausson B, Granath F, Ekbom A, et al. Effect of caffeine exposure during pregnancy on birth weight and gestational age. Am J Epidemiol 2002;155:429-36.

76 Bakker R, Steegers EAP, Obradov A, et al. Maternal caffeine intake from coffee and tea, fetal growth, and the risks of adverse birth outcomes: the generation R study. Am J Clin Nutr 2010;91:1691-8.

77 Sengpiel V, Elind E, Bacelis J, et al. Maternal caffeine intake during pregnancy is associated with birth weight but not with gestational length: results from a large prospective observational cohort study. BMC Med 2013;11:42.

78 Bech BH, Frydenberg M, Henriksen TB, et al. Coffee consumption during pregnancy and birth weight: does smoking modify the association? J Caffeine Res 2015;5:65-72.

79 Okubo H, Miyake Y, Tanaka K, et al. Maternal total caffeine intake, mainly from Japanese and Chinese tea, during pregnancy was associated with risk of preterm birth: the Osaka Maternal and Child Health Study. Nutr Res 2015;35:309-16.

80 Santos IS, Victora CG, Huttly S, et al. Caffeine intake and pregnancy outcomes: a meta-analytic review. Cad Saude Publica 1998;14:523-30.

81 Chen L-W, Wu Y, Neelakantan N, et al. Maternal caffeine intake during pregnancy is associated with risk of low birth weight: a systematic review and dose-response meta-analysis. BMC Med 2014;12:174.

82 Rhee J, Kim R, Kim Y, et al. Maternal caffeine consumption during pregnancy and risk of low birth weight: a dose-response meta-analysis of observational studies. PLoS One 2015;10:e0132334.

83 Chiaffarino F, Parazzini F, Chatenoud L, et al. Coffee drinking and risk of preterm birth. Eur J Clin Nutr 2006;60:610-3.

84 Maslova E, Bhattacharya S, Lin S-W, et al. Caffeine consumption during pregnancy and risk of preterm birth: a meta-analysis. Am J Clin Nutr 2010;92:1120-32.

85 Hunger SP, Mullighan CG. Acute lymphoblastic leukemia in children. $N$ Engl J Med 2015;373:1541-52.

86 Menegaux F, Ripert M, Hémon D, et al. Maternal alcohol and coffee drinking, parental smoking and childhood leukaemia: a French population-based case-control study. Paediatr Perinat Epidemiol 2007;21:293-9.

87 Bonaventure A, Rudant J, Goujon-Bellec S, et al. Childhood acute leukemia, maternal beverage intake during pregnancy, and metabolic polymorphisms. Cancer Causes Control 2013;24:783-93.

88 Milne E, Greenop KR, Petridou E, et al. Maternal consumption of coffee and tea during pregnancy and risk of childhood all: a pooled analysis from the Childhood Leukemia International Consortium. Cancer Causes Control 2018;29:539-50.

89 Milne E, Royle JA, Bennett LC, et al. Maternal consumption of coffee and tea during pregnancy and risk of childhood ALL: results from an Australian case-control study. Cancer Causes Control 2011;22:207-18.

90 Karalexi MA, Dessypris N, Clavel J, et al. Coffee and tea consumption during pregnancy and risk of childhood acute myeloid leukemia: a Childhood Leukemia International Consortium (CLIC) study. Cancer Epidemiol 2019;62:101581.

91 Orsi L, Rudant J, Ajrouche R, et al. Parental smoking, maternal alcohol, coffee and tea consumption during pregnancy, and childhood acute leukemia: the ESTELLE study. Cancer Causes Control 2015;26:1003-17.

92 Cheng J, Su H, Zhu R, et al. Maternal coffee consumption during pregnancy and risk of childhood acute leukemia: a metaanalysis. Am J Obstet Gynecol 2014;210:151.e1-10.

93 Thomopoulos TP, Ntouvelis E, Diamantaras A-A, et al. Maternal and childhood consumption of coffee, tea and cola beverages in association with childhood leukemia: a meta-analysis. Cancer Epidemiol 2015;39:1047-59.

94 Xu D, Zhang B, Liang G, et al. Caffeine-induced activated glucocorticoid metabolism in the hippocampus causes hypothalamic-pituitary-adrenal axis inhibition in fetal rats. PLoS One 2012;7:e44497.

95 Li J, Luo H, Wu Y, et al. Gender-specific increase in susceptibility to metabolic syndrome of offspring rats after prenatal caffeine exposure with post-weaning high-fat diet. Toxicol Appl Pharmacol 2015b;284:345-53.

96 Rivkees SA, Wendler CC. Adverse and protective influences of adenosine on the newborn and embryo: implications for preterm white matter injury and embryo protection. Pediatr Res 2011;69:271-8.

97 Buscariollo DL, Fang X, Greenwood V, et al. Embryonic caffeine exposure acts via A1 adenosine receptors to alter adult cardiac function and DNA methylation in mice. PLoS One 2014;9:e87547.

98 Wu Y-M, Luo H-W, Kou H, et al. Prenatal caffeine exposure induced a lower level of fetal blood leptin mainly via placental mechanism. Toxicol Appl Pharmacol 2015;289:109-16. 
99 DK L, Ferber JR, Odouli R. Maternal caffeine intake during pregnancy and risk of obesity in offspring: a prospective cohort study. Int J Obes 2015;39:658-64.

100 Papadopoulou E, Botton J, Brantsæter A-L, et al. Maternal caffeine intake during pregnancy and childhood growth and overweight: results from a large Norwegian prospective observational cohort study. BMJ Open 2018;8:e018895.

101 Chen L-W, Murrin CM, Mehegan J, et al. Maternal, but not paternal or grandparental, caffeine intake is associated with childhood obesity and adiposity: the Lifeways Cross-Generation Cohort Study. Am J Clin Nutr 2019;109:1648-55.

102 Klebanoff MA, Keim SA. Maternal serum paraxanthine during pregnancy and offspring body mass index at ages 4 and 7 years. Epidemiology 2015;26:185-91.

103 McCoy GM, Evans EL. Caffeine intake during pregnancy and weight of offspring in childhood: a systematic review., 2019. Med Health Sci Commons. Available: https://commons.pacificu.edu/pa/661

104 James JE. Caffeine, health and commercial interests. Addiction 1994;89:1595-9.

105 James JE. Third party threats to research integrity in public-private partnerships. Addiction 2002;97:1251-5.

106 Pendergrast M. Uncommon grounds: the history of coffee and how it transformed our world. New York, NY: Basic Books, 1999.

107 Demortain D. Are scientists agents of corporate power on public policy? Corporations and the use of science for diffuse lobbying strategies. Paper presented at the Pervasive Powers, Corporate Authority and Public Policy Conference; 15-16 June, Universitat Paris-Dauphine, Paris, 2018.

108 Greenhalgh S. Making China safe for coke: how Coca-Cola shaped obesity science and policy in China. BMJ 2019;357:k5050.

109 Greenhalgh S. Science and serendipity: finding Coca-Cola in China. Perspect Biol Med 2019;62:131-52.

110 Grimm H-U. Information-domination in the European food industry: focus on Germany. In: Steier G, Patel K, eds. International food law and policy. Cham, Switzerland: Springer, 2016: 3-30.

111 MacDonald R. WHO says tobacco industry "used" institute to undermine its policies. BMJ 2001;322:576.

112 Strassheim H, Loer K. Who are the policymakers and what are their interests? In: Ewert B, Loer K, eds. Behavioural policies for health promotion and disease prevention. Cham, Switzerland: Palgrave Pivot, 2019: 73-92.

113 Zeltner T, Kessler DA, Martiny A, et al. Tobacco company strategies to undermine tobacco control activities at the World Health Organization. Geneva: World Health Organization, 2000. https://www.who.int/tobacco/ publications/industry/who_inquiry/en/

114 Leviton A. Epidemiologic studies of birth defects. In: Dews PB, ed. Caffeine: perspectives from recent research. Berlin: Springer-Verlag, 1984: 188-200.

115 Leviton A. Caffeine consumption and the risk of reproductive hazards. $J$ Reprod Med 1988;33:175-8.

116 Leviton A, Cowan L. A review of the literature relating caffeine consumption by women to their risk of reproductive hazards. Food Chem Toxicol 2002;40:1271-310.
117 Peck JD, Leviton A, Cowan LD. A review of the epidemiologic evidence concerning the reproductive health effects of caffeine consumption: a 2000-2009 update. Food Chem Toxicol 2010;48:2549-76.

118 Doepker C, Lieberman HR, Smith AP, et al. Caffeine: friend or foe? Annu Rev Food Sci Technol 2016;7:117-37.

119 Wikoff D, Welsh BT, Henderson R, et al. Systematic review of the potential adverse effects of caffeine consumption in healthy adults, pregnant women, adolescents, and children. Food Chem Toxicol 2017;109:585-648.

120 Doepker C, Franke K, Myers E, et al. Key findings and implications of a recent systematic review of the potential adverse effects of caffeine consumption in healthy adults, pregnant women, adolescents, and children. Nutrients 2018;10:1536.

121 Leviton A. Biases inherent in studies of coffee consumption in early pregnancy and the risks of subsequent events. Nutrients 2018;10:1152.

122 Meyer LC, Peacock JL, Bland JM, et al. Symptoms and health problems in pregnancy: their association with social factors, smoking, alcohol, caffeine and attitude to pregnancy. Paediatr Perinat Epidemiol 1994;8:145-55.

123 Sapra KJ, Joseph KS, Galea S, et al. Signs and symptoms of early pregnancy loss: a systematic review. Reprod Sci 2017;24:502-13.

124 Stein Z, Susser M. Miscarriage, caffeine, and the epiphenomena of pregnancy: the causal model. Epidemiology 1991;2:163-7.

125 Boylan SM, Greenwood DC, Alwan N, et al. Does nausea and vomiting of pregnancy play a role in the association found between maternal caffeine intake and fetal growth restriction? Matern Child Health J 2013;17:601-8.

126 Jahanfar S, Jaafar SH. Effects of restricted caffeine intake by mother on fetal, neonatal and pregnancy outcomes. Cochrane Database Syst Rev 2015:CD006965.

127 Bech BH, Obel C, Henriksen TB, et al. Effect of reducing caffeine intake on birth weight and length of gestation: randomised controlled trial. BMJ 2007;334:409.

128 Martin JA, Hamilton BE, Osterma MJK, et al. Births: final data for 2017. National Vital Statistics Reports. 66. Washington, DC: Centers for Disease Control and Prevention, 2017. https://www.cdc.gov/nchs/data/nvsr/ nvsr66/nvsr66_01.pdf

129 Martin JA, Hamilton BE, Osterma MJK, et al. Births: final data for 2017. National Vital Statistics Reports. 67. Washington, DC: Centers for Disease Control and Prevention, 2018. https://www.cdc.gov/nchs/data/nvsr/ nvsr67/nvsr67_08-508.pdf

130 Curtin SC, Abma JC, Ventura SJ, et al. Pregnancy rates for U.S. women continue to drop. National Center for Health Statistics Data Brief, no. 136. Washington, DC: Centers for Disease Control and Prevention, 2013. https://www.cdc.gov/nchs/data/databriefs/db136.pdf

131 Hoyert DL, Gregory ECW. Cause of fetal death: data from the fetal death report, 2014. National Vital Statistics Reports. 65. Washington, DC: Centers for Disease Control and Prevention, 2016. https://www.cdc.gov/ nchs/data/nvsr/nvsr65/nvsr65_07.pdf

132 Ewing AC, Ellington SR, Shapiro-Mendoza CK, et al. Full-term smallfor-gestational-age newborns in the U.S.: characteristics, trends, and morbidity. Matern Child Health J 2017;21:786-96. 